Conclusion: NTK demonstrated rapid improvement in QoL, work productivity and physical function in pts with PsA.

Acknowledgments: This study was sponsored by JSC BIOCAD.

Disclosure of Interests: Tatiana Korotaeva Consultant of: Pfizer, MSD, Novartis, AbbVie, Celgene, JSC BIOCAD, Janssen, UCB, Lilly and Novartis-Sandoz, Speakers bureau: Pfizer, MSD, Novartis, AbbVie, Celgene, JSC BIOCAD, Janssen, UCB, Lilly and Novartis-Sandoz, Inna Gaydukova Grant/research support from: JSC BIOCAD, Speakers bureau: Pfizer, Novartis, AbbVie, JSC BIOCAD, Celgene, MSD, Sanofi, V Mazurov: None declared, Aleksey Samtsov Grant/ research support from: JSC BIOCAD, Novartis, Eli Lilly, Johnson\&Johnson, Celgene, Glenmark, Galderma, Sanofi, Vladislav Khayrutdinov Grant/research support from: Akrikhin, Alkoy, Belupo, JSC BIOCAD, Bosnaliejk, Verteks, Glenmark, Elfa, Leo Pharma, MSD, Novartis, Pfizer, Sun Pharma, Sanofi, Celgene, Pharmtec, AbbVie, Eli Lilly, Jadran, Janssen, Andrey Bakulev Grant/research support from: AbbVie, Eli Lilly, Pfizer, UCB, MSD, Novartis, Galderma, Celgene, Leo Pharma and Johnson\&Johnson, JSC BIOCAD, Consultant of: Novartis, Celgene and Johnson\&Johnson, Speakers bureau: AbbVie, Eli Lilly, Galderma, UCB, Novartis, Celgene and Johnson\&Johnson, Muza Kokhan Grant/research support from: AbbVie, Eli Lilly, Pfizer, UCB, MSD, Novartis, Galderma, Celgene, Leo Pharma and Johnson\&Johnson, JSC BIOCAD, Consultant of: Novartis, Celgene and Johnson\&Johnson, Speakers bureau: AbbVie, Eli Lilly, Galderma, UCB, Novartis, Celgene and Johnson\&Johnson, Alena Kundzer: None declared, Nikolaj Soroka Grant/research support from: JSC BIOCAD, Ekaterina Dokukina Employee of: JSC BIOCAD, Anna Eremeeva Employee of: JSC BIOCAD DOI: 10.1136/annrheumdis-2020-eular.3593

\section{AB0793 1 CHANGES IN PSAID-12 SCORES BEFORE AND AFTER BIOLOGICAL TREATMENT IN PATIENTS WITH} PSORIATIC ARTHRITIS

A. Sahin Eskara ${ }^{1}$, G. Er ${ }^{1}$, I. Oguz Topal ${ }^{2}$, Y. Arıcan Zahiroglu ${ }^{3}$, O. Kuru ${ }^{4}$. ${ }^{1}$ University of Health Sciences, Okmeydanı Training and Research Hospital, Physical Medicine and Rehabilitation, Istanbul, Turkey; ${ }^{2}$ University of Health Sciences, Okmeydanı Training and Research Hospital, Dermatology, Istanbul, Turkey; ${ }^{3}$ University of Health Sciences, Samsun Training and Research Hospital, Rheumatology, Samsun, Turkey; ${ }^{4}$ University of Health Sciences, Okmeydanı Training and Research Hospital, Physical Medicine and Rehabilitation, Division of Rheumatology, Istanbul, Turkey

Background: Psoriatic Arthritis Impact of Disease 12-item questionnaire (PsAID-12) is a patient-reported outcome measure (PROM) which allows a more precise assessment of the impact of PsA and helps treatment decisions geared to either disease activity or, for example, physpsychological distress $(1,2)$.

Objectives: Our objective is to evaluate change of PSAID-12 values after threemonths biologic drug treatment and to find out its relationship with other quality of life indices and disease activity parameters in PsA patients

Methods: Patients with a diagnosis of PSA according to CASPAR criteria were recruited to the study. The data of the patients before and after three-month treatment were evaluated retrospectively. The number of swollen (0-66) and tender joints (TJ) (0-68), ESR, CRP, Patient Global Assessment(PGA), physician's global assessment (PhGA),DAPSA and BASDAI were used for the assessment of disease activity. Functional status was assessed with BASFI, quality of life with EuroQol, DLQI and HAQ. Enthesitis evaluation was performed with MASES. Dermatological assesment was done with BSA and PASI. In addition, PSARC and MDA criteria was used to assess patient's response to treatment. A p-value less than 0.05 was statistically significant. Results: Fifteen patients who met the study criteria were evaluated. 3 patients were excluded because of irregular drug usage. 9 of the 12 patients were women, the average age was 46,41 , and BMI was 32,68 . Both acute phase reactants were decreased after treatment, and there was significant decrease at CRP levels but not at ESR. It was also observed that there were significant differences at PGA, PhGA, BASDAI, BASFI, MASES, DAPSA and PSAID-12 scores after treatment. There were no statistically significant differences at number of swollen and tender joints, HAQ,EuroQol, PASI, BSA and DLQI scores. 3 patients achieved MDA and 7 patients achieved PSARC criteria. There were statistically significant correlations between pre-treatment mean scores of PSAID-12 and BASDAI, BASFI, DAPSA, $H A Q$, EuroQol, PhGA. There were statistically significant correlations between after-treatment mean scores of PSAID-12 and BASDAI, DAPSA, PASI and BSA. The correlations between PSAID-12 change ( $\triangle$ PSAID-12) with other outcome measure changes were as follows: $\triangle \mathrm{HAQ}(r=0,27, p=0,39), \triangle \mathrm{BASDAI}(r=0.37, p=0,22)$, $\triangle \mathrm{PGA}(\mathrm{r}=0.28, \mathrm{p}=0,36), \Delta \mathrm{DLQ}$ ( $\mathrm{r}=0.71, \mathrm{p}=0,17), \Delta \mathrm{BASFI}(\mathrm{r}=0.41, \mathrm{p}=0,18), \Delta \mathrm{ESR}$ $(r=0,20, p=0,55)$, and $\Delta C R P(r=-0.39, p=0,20), \triangle D A P S A(r=0,77, p=0,009), \Delta$ number of TJ $(r=0,81, p=0,004), \Delta$ MASES $(r=0,57, p=0,08), \Delta$ EuroQol $(r=-0,29, p=0,34)$, $\triangle \mathrm{PASI}(\mathrm{r}=0,30, p=0,62)$. It is also observed that PsAID-12 scores decreased more in PSARC responders rather than non-responders, but this difference was not statistically significant. No cases of major adverse event were reported.

Conclusion: PSAID-12 evaluates effect of both physical and psychosocial aspects of PSA and shows close relationship with other PROMS but it may be inadequate in assessing biological treatment response in PsA.

\section{References:}

[1] Kalyoncu, Umut, et al. "Change in PSAID-12 scores in patients continuing or discontinuing anti-TNF treatments in psoriatic arthritis: results from the HUR-BIO biologic registry." Clinical rheumatology 38.4 (2019): 1187-1192.

[2] Gossec, Laure, et al. "A patient-derived and patient-reported outcome measure for assessing psoriatic arthritis: elaboration and preliminary validation of the Psoriatic Arthritis Impact of Disease (PsAID) questionnaire, a 13-country EULAR initiative." Annals of the rheumatic diseases 73.6 (2014): 1012-1019.

Disclosure of Interests: None declared

DOI: 10.1136/annrheumdis-2020-eular.3667

\section{AB0794 \\ CLINICAL TRIAL DISCRIMINATION OF PHYSICAL FUNCTION INSTRUMENTS FOR PSORIATIC ARTHRITIS: A SYSTEMATIC REVIEW}

Y.Y. Leung ${ }^{1}$, R. Holland ${ }^{2}$, A. Mathew ${ }^{3}$, C. Lindsay ${ }^{4}$, N. Goel ${ }^{5}$, A. Ogdie ${ }^{6}$, A. M. Orbai ${ }^{7}$, P. Hoejgaard ${ }^{8}$, J. Chau ${ }^{9}$, L. C. Coates ${ }^{10}$, V. Strand ${ }^{11}$, D. D. Gladman ${ }^{12}$, R. Christensen ${ }^{13}$, W. Tillett ${ }^{14}$, P. J. Mease ${ }^{15}$. ${ }^{1}$ Singapore General Hospital, Singapore, Singapore; ${ }^{2}$ Concord Repatriation General Hospital, Sydney, Australia; ${ }^{3}$ Christian Medical College, Vellore, India; ${ }^{4}$ Patient Research Partner, Taxas, United States of America; ${ }^{5}$ Patient research partner, Duke University, Durham, United States of America; ${ }^{6}$ University of Pennsylvania, Pennsylvania, United States of America; ${ }^{7}$ Johns Hopkins University School of Medicine, Baltimore, United States of America; ${ }^{8}$ Rigshospitalet University Hospital, Copenhagen, Denmark; ${ }^{9}$ Patient Research Partner, Hong Kong, Hong Kong (SAR); ${ }^{10}$ Oxford University, Oxford, United Kingdom; ${ }^{11}$ Stanford University School of Medicine, Stanford, United States of America; ${ }^{12}$ University of Toronto, Toronto, United States of America; ${ }^{13}$ The Parker Institute, Copenhagen, Denmark; ${ }^{14}$ University of Bath, Bath, United Kingdom; ${ }^{15}$ Swedish Medical Center/ Providence St. Joseph Health, Seattle, United States of America

Background: Physical function is a core domain to be measured in randomized controlled trials (RCTs) of psoriatic arthritis (PsA). The discriminative

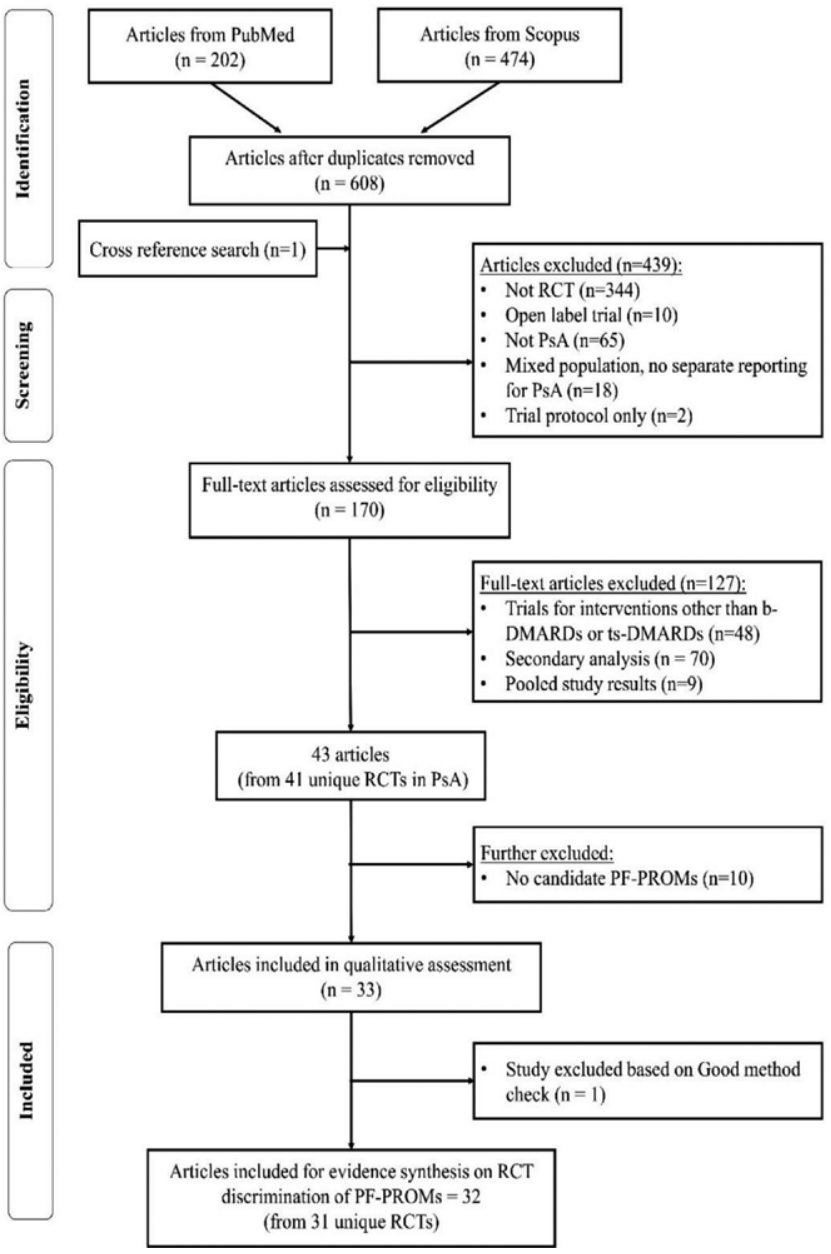

Figure 1. Article selection 